San Jose State University

SJSU ScholarWorks

Faculty Publications

Economics

$1-1-1983$

\title{
A Firm's Bid Price Curve and the Neoclassical Theory of Production: A Correction and Further Analysis
}

Yeung-Nan Shieh

San Jose State University, yeung-nan.shieh@sjsu.edu

C. C. Mai

Follow this and additional works at: https://scholarworks.sjsu.edu/econ_pub

Part of the Economics Commons

\section{Recommended Citation}

Yeung-Nan Shieh and C. C. Mai. "A Firm's Bid Price Curve and the Neoclassical Theory of Production: A Correction and Further Analysis" Southern Economic Journal (1983): 230-233.

This Article is brought to you for free and open access by the Economics at SJSU ScholarWorks. It has been accepted for inclusion in Faculty Publications by an authorized administrator of SJSU ScholarWorks. For more information, please contact scholarworks@sjsu.edu. 


\section{A Firm's Bid Price Curve and The Neoclassical Theory of Production: A Correction and Further Analysis*}

\section{Introduction}

This paper is an extension of a recent paper in this journal [2] in which one of the authors developed an alternative rent-maximization approach to integrate the neoclassical production theory with location theory and re-examine the basic properties of the bid price curve of the urban firm. The earlier paper considered only the fixed output case and attempted to show that (i) the bid price curve is convex to the origin if the output price declines at a decreasing rate with distance and (ii) the curve is a straight line if the output price declines at a constant rate with distance. Unfortunately, the derivation of these results contained an error. This paper will demonstrate that the bid price curve is convex to the origin, whether output price declines at a decreasing or constant rate with distance. In addition, we will extend the rent maximization approach to the case where output is not held constant. Such an examination is important because the variable output case is more realistic. In particular, this paper will show that in the case of variable output the convexity of the bid price curve is, in general, indeterminate.

\section{The Fixed Output Case Revisited}

In this section, we set forth the basic model to be used in the analysis below. It is essentially the same model used in the earlier paper [2] so that this paper can be self-contained.

Following Alonso [1] and Mai [2], we consider a featureless plain upon which sits an urban center where all economic activities take place. The land surrounding this center is allocated to some sets of households, farms and firms through the operation of the real estate market. The firms which participate in this auction can combine land and labor to produce a standardized product. The production function of the firm can be specified as:

$$
Q=f(N, L)
$$

where $L=$ the land input, $N=$ the labor input and $Q=$ output.

Next, the representative firm's profit function can be given by:

$$
G=p(t) Q-w N-R(t) L, \quad p^{\prime}(t)<0
$$

\footnotetext{
* We are indebted to R. Anderson, S. Bostaph, K. Hohlt, D. Kleykamp, M. L. Shieh and especially anonymous referees for many useful discussions and comments. Responsibility for all errors remains with the authors.
} 
where $p(t)=$ the price of output, $w=$ the constant wage rate, $R(t)=$ the rent of land per unit area and $t=$ the distance from the firm's location to the urban center.

Based on the rent maximization approach, we define the bid price curve as the schedule of maximum rent (per unit land) which the firm would be willing to pay for given locations, while still keeping itself at a particular level of profits, $G_{o}$ and output, $Q_{o}$. Thus, the firm wishes to organize production by choosing land and labor so as to

$$
\max R(N, L) \quad \text { s.t. } Q_{o}=f(N, L)
$$

where $R(N, L)=(1 / L)\left[p(t) Q_{o}-w N-G_{o}\right]$.

The Lagrangian function can be formed as:

$$
H\left(N, L, \lambda, t, G_{o}, w, Q_{o}\right)=(1 / L)\left[p(t) Q_{o}-w N-G_{o}\right]+\lambda\left[f(N, L)-Q_{o}\right]
$$

where $\lambda$ is the Lagrangian multiplier. Differentiating (4) with respect to $N, L$ and $\lambda$ and setting each expression equal to zero, we obtain the first-order conditions for this constrained maximization problem. The first-order conditions give us the optimal values of $N, L$ and $\lambda$ in terms of parametrically given variables $t, G_{o}, w$ and $Q_{o}$. By using the well-known envelope theorem of comparative statics, we obtain

$$
\partial R^{*}(\alpha) / \partial t=\partial H\left(N^{*}(\alpha), L^{*}(\alpha), \lambda^{*}(\alpha), \alpha\right) / \partial t=p^{\prime}(t) Q_{o} / L^{*}(\alpha)<0
$$

where $R^{*}(\alpha)=R\left(N^{*}(\alpha), L^{*}(\alpha), \alpha\right), \alpha=\left(t, G_{o}, w, Q_{o}\right)$, and $N^{*}(\alpha), L^{*}(\alpha)$, and $\lambda^{*}(\alpha)$ are the optimal values of $N, L$, and $\lambda$. Notice that the partial derivative of $H$ is with respect to its fourth argument (see equation 4).

In order to examine the shape of the bid price curve, we differentiate (5) with respect to $t$ to yield

$$
\partial^{2} R^{*}(\alpha) / \partial t^{2}=\left(Q_{o} / L^{*}(\alpha)\right)\left[p^{\prime \prime}(t)-\left(L_{t}^{*} / L^{*}(\alpha)\right) p^{\prime}(t)\right]
$$

where $L_{t}^{*} \equiv\left(\partial L^{*}(\alpha) / \partial t\right)=-(1 / D)\left[p^{\prime}(t) Q_{o} / L^{*}(\alpha)\right] f_{N}^{2}>0$ and $D=-\left(w / f_{N}\right)\left(f_{L}^{2} f_{N N}-\right.$ $\left.2 f_{L} f_{N} f_{N L}+f_{N}^{2} f_{L L}\right)>0$ if $f$ is strictly concave. Equation (6) is what should have appeared as equation (14) in Mai's earlier paper. ${ }^{1}$ Since $L_{t}^{*}>0$ and $p^{\prime}(t)<0$, it follows from (6) that if $p^{\prime \prime}(t) \geqq 0, \partial^{2} R^{*}(\alpha) / \partial t^{2}>0$. Hence, we can establish our proposition that the bid price curve is convex to the origin if the output price declines at a decreasing or constant rate with distance. Therefore, Mai's assertion that the bid price curve is a straight line if the output price declines at a constant rate is invalid [2,895].

So far, we have considered the fixed output case. We now turn to the more realistic case where output per unit of land is allowed to be different at different locations.

\section{The Variable Output Case}

In the variable output case, the urban firm decides the input combination and the output level that would maximize its rent as specified as

$$
R(N, L)=(1 / L)\left[p(t) f(N, L)-w N-G_{o}\right]
$$

The first-order conditions are:

1. There is a misprint " $p "(t)<0$ " in the earlier paper [2,895]. It should have been read " $p "(t)>0$ " 


$$
\begin{aligned}
(\partial R / \partial N) & =(1 / L)\left[p(t) f_{N}-w\right]=0 \\
(\partial R / \partial L) & =\left(1 / L^{2}\right)\left\{L p(t) f_{L}-\left[p(t) f(N, L)-w N-G_{o}\right]\right\}=0 .
\end{aligned}
$$

We assume that the production function $f$ is strictly concave which implies that

$$
R_{N N}<0 \text { and } D \equiv R_{N N} R_{L L}-R_{L N}^{2}>0
$$

for all $(N, L)$. Therefore, the function $R$ is maximized at positive solutions to equations (8a) and (8b). These solutions depend upon the parameters $t, w$, and $G_{o}$.

$$
\begin{aligned}
N & =N^{*}\left(t, w, G_{o}\right) \\
L & =L^{*}\left(t, w, G_{o}\right) .
\end{aligned}
$$

To examine the basic properties of the bid price curve, we first substitute (10) into (7) to obtain the bid price function as

$$
R^{*}\left(t ; G_{o}, w\right)=\left[1 / L^{*}(\cdot)\right]\left\{p(t) f\left(N^{*}(\cdot), L^{*}(\cdot)\right]-w N^{*}(\cdot)-G_{o}\right\} .
$$

Equation (11) describes the relationship between the rent of land per unit area and the distance in terms of $w$ and $G_{o}$ under the variable output case.

From (11), we obtain, via the envelope theorem, ${ }^{2}$

$$
\begin{aligned}
\left(\partial R^{*} / \partial t\right) & =\left(1 / L^{*}\right) p^{\prime}(t) f\left(N^{*}, L^{*}\right)<0 \\
\left(\partial R^{*} / \partial G_{o}\right) & =-\left(1 / L^{*}\right)<0 \\
\left(\partial R^{*} / \partial w\right) & =-\left(N^{*} / L^{*}\right)<0 .
\end{aligned}
$$

Clearly, equations (12) and (13) indicate two important properties of bid price curves established by Alonso. (i) The bid price function will slope downward; (ii) higher profits levels at a particular location are associated with lower bid prices. Equation (14) indicates that higher wage levels at a particular location are associated with lower bid prices.

Next, let us examine the shape of the bid price curve. Taking the derivative of (12) with respect to $t$ yields

$$
\left(\partial^{2} R^{*} / \partial t^{2}\right)=\left(Q / L^{*}\right)\left[p^{\prime \prime}(t)-p^{\prime}(t)\left(L_{t}^{*} / L^{*}\right)\right]+\left[p^{\prime}(t) / L^{*}\right]\left(f_{N} N_{t}^{*}+f_{L} L_{t}^{*}\right)
$$

where

$$
\begin{aligned}
& L_{t}^{*}=\left(1 / D^{*}\right)\left(p p^{\prime} / L^{* 2}\right)\left[\left(1 / L^{*}\right)\left(Q-L^{*} f_{L}\right) f_{N N}+f_{N} f_{L N}\right] \\
& N_{t}^{*}=\left(-1 / D^{*}\right)\left(p p^{\prime} / L^{* 2}\right)\left[\left(1 / L^{*}\right)\left(Q-L^{*} f_{L}\right) f_{N L}+f_{N} f_{L L}\right] .
\end{aligned}
$$

It follows from (15) that even if $p^{\prime}(t)<0$ and $p^{\prime \prime}(t) \geqq 0$, the sign of (15) is ambiguous. Thus, the shape of the bid price curve is indeterminate.

\section{Conclusion}

In this paper, we have re-examined the bid price curve of an urban firm under the fixed output case and extended it to the more realistic case where output is not held constant. In

2. For details, see Silberberg [3,168-71 and Chapter 9]. 
the fixed output case, we have shown that the bid price curve of an urban firm is always convex to the origin if the output price declines at a decreasing or constant rate with distance. Furthermore, under the same set of conditions, we have shown that although Alonso's three important properties of a bid price curve can be maintained in the variable output case, the shape of the curve is unfortunately indeterminate.

Yeung-nan Shieh University of Dallas Irving, Texas

Chao-Cheng Mai Academia Sinica

Taiwan

\section{References}

1. Alonso, W. Location and Land Use: Toward a General Theory of Land Rent. Cambridge: Harvard University Press, 1964.

2. Mai, C. C., "A Firm's Bid Price Curve and The Neoclassical Theory of Production." Southern Economic Journal, January, 1980, 892-97.

3. Silberberg, E. The Structure of Economics. New York: McGraw-Hill, 1978. 